\title{
Temporary fixes to chronic drug shortages leave Canada vulnerable
}

\author{
— Cite as: CMAJ 2020 August 4;192:E898-9. doi: 10.1503/cmaj.1095886
}

Posted on cmajnews.com on July 16, 2020

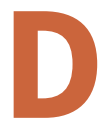

octors and pharmacists are working around shortages of critical care medicines but warn that stop-gap measures can only stretch supplies so far.

Of the 32 drugs on Health Canada's list of "tier 3" shortages posing the greatest threat to the health system, 24 are used in the treatment of coronavirus disease 2019 (COVID-19) or related conditions. These include key sedatives, pain medications and paralytic agents for patients on ventilators and those undergoing surgery.

Patients with COVID-19 consume these drugs at double or triple the rate of other intensive care patients. Manufacturers struggled to keep up with this additional demand as the virus spread globally and disrupted supply chains in countries like China and India. Meanwhile, the increasing consolidation of the pharmaceutical industry in recent years has meant there are fewer alternative sources for drugs and ingredients to fall back on during crises.

\section{Rising to the crisis}

So far, Canada has drawn on lessons from previous shortages to avoid major disruptions in care, says Dr. James Downar, a critical care physician at the Ottawa Hospital and head of palliative care at the University of Ottawa.

"This isn't our first rodeo," Downar says, recalling shortfalls of more than 1000 drugs that followed a fire at a Quebec factory in 2012. "We developed processes around that time that we're using now. We've had experience figuring out how to allocate medications better and how to switch around to different classes or use different medications in the same class," he says.

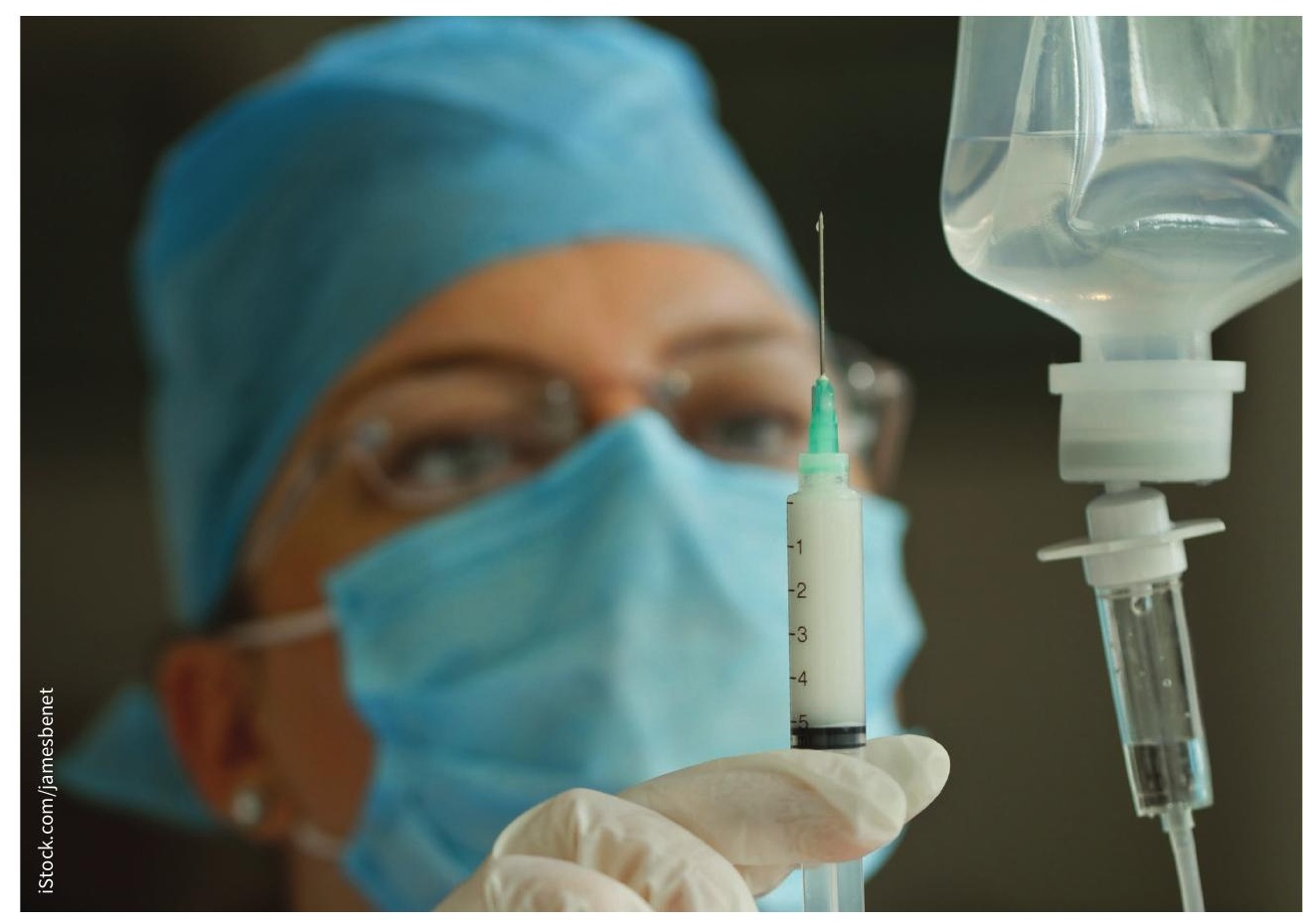

Canada may face dire shortages of critical care medicines if a second wave of COVID-19 cases spikes earlier than anticipated.

Canada has seen a steady increase in drug shortages over the past two years, with an uptick of 369 new shortages in March and April this year, compared to 163 in January and February.

In response, Health Canada issued an interim order allowing the import and sale of international versions of drugs on the tier 3 shortage list that may not meet Canadian regulatory and labelling requirements. The federal government has also issued requests for information or letters of interest to "identify additional supply" of essential critical care drugs.

In the case of the sedative propofol, Health Canada has expedited imports from the European Union, and providers can use alternatives such as ketamine (although that drug also appears on the tier 3 shortage list). Ontario are collecting information on stock levels within their jurisdictions and advising hospitals on rationing existing supplies.

According to Christina Adams, chief pharmacy officer with the Canadian Society of Hospital Pharmacists, current supplies of critical care drugs should last into the fall, so long as patient volumes remain low. All bets are off, though, should Canada see a spike in cases of COVID-19 before then.

Maintaining a relative lull in cases through the summer is allowing drug
In the meantime, provinces like 
manufacturers worldwide to ramp up production in anticipation of a second wave, Adams explains. But Canada's supply chain remains vulnerable to other disruptions, "for example, a lack of raw material or trade restrictions."

\section{Rethinking Canada's response}

A group of physicians, pharmacists, and pharmaceutical industry insiders blames Canada's heavy reliance on foreign manufacturers. More than a third of all drugs are produced by just 10 companies, which have increased outsourcing of all stages of production over the past two decades.

"We have driven costs so low on many generics that a lot of manufacturing has left this country and gone to the lowest cost centres in India and China," says Dr. Kashif Pirzada, an emergency physician in Toronto and founding member of the Critical Drugs Coalition. This becomes a problem in global crises when countries like India restrict exports to shore up local supplies.

The coalition is advocating for Canada to increase domestic production of essential medicines and transparency around shortages. Although Health Canada now requires drug companies to report shortages and discontinuations, many other links in the supply chain remain opaque, says Pirzada. This includes stock levels at pharmacies across the country. "It's a big black box, which I think needs to be cleared up," he says.

Pirzada recognizes that manufacturing more medicines domestically would likely come with a hefty price tag (and Canada already pays some of the highest drug prices globally). But he argues that producing a "redundancy" of 10\%-15\% of medicines in Canada would provide a margin of safety in future crises.

Downar agrees that reducing Canada's reliance on any one company or country makes good sense. "A number of countries and regions will probably start to try to diversify their supply chain a bit, so that we're not as susceptible to specific events that affect one supplier," he says.

However, Adams notes that boosting domestic production of medicines wouldn't address shortages of active pharmaceutical ingredients, about $80 \%$ of which come from overseas. Instead, she supports building a national reserve of essential medications. The main challenge would be identifying how much to stockpile to avoid a repeat of the 2010 Tamiflu debacle, in which millions of doses expired before they could be used.

"I would say once things start to calm down with this current pandemic, there'll be a reevaluation of how drug shortages are handled," Adams says.

Greg Basky, Saskatoon, Sask. 